\title{
EFFICACY OF PULSED ELECTROMAGNETIC FIELD ON PAIN AND FUNCTION IN CHRONIC MECHANICAL NECK PAIN: A RANDOMIZED CONTROLLED TRIAL
}

\section{Mohamed Salaheldien Alayat *1, Mohamed Mohamed Ibrahim Ali ${ }^{2}$, Amir Abdel Raouf El Fiky ${ }^{3}$, Mansour Abdullah Alshehri ${ }^{4}$.}

${ }^{* 1}$ Assistant Professor of Physical Therapy, Department of Basic Science, Faculty of Physical Therapy, Cairo University. Egypt.

${ }^{2}$ Assistant Professor of Physical therapy, Department of Orthopedic Physical Therapy, Faculty of Physical Therapy, Cairo University, EGYPT.

${ }^{3}$ Lecturer Physical Therapy, Physical Therapy for Neurological Disorders and its Surgery, Faculty of Physical Therapy, Cairo University, Giza, Egypt.

${ }^{4}$ Lecturer Physical Therapy, Physiotherapy and rehabilitation department, Faculty of Applied Medical Science, Umm Al-Qura University, Mecca, Saudi Arabia.

\section{ABSTRACT}

Background: Mechanical neck pain (MNP) is a common neck disorders affecting middle-aged population. Magnetotherapy is considered as a safe and non-invasive physical therapy modality used in the treatment of musculoskeletal pain.

Subjects and Methods: A total of 60 male patients participated in this study. Their mean age, weight, height, body mass index (BMI) and duration of illness were 23.03 (2.239) years, 63.43 (5.195) Kg, $1.662(5.1092) \mathrm{cm}, 22.98$ $(1.879) \mathrm{Kg} / \mathrm{m}^{2}, 4.483(1.228)$ months respectively. They were randomly assigned in to two groups. Group I (30 Patients) was treated with PEMF plus exercises (PEMF+EX) group and group II (30 Patients) treated with placebo magnetic plus exercises (PL+EX) group. Exercise program included active range of motion, muscle stretching and strengthening exercises applied two sessions/week for 6 weeks. PEMF was applied with $20 \mathrm{~Hz}, 0.8 \mathrm{mT}$ for 20 minutes two sessions/week for 6 weeks. Pain level was measured by visual analog scale (VAS) and neck functions were measured by neck disability index (NDI). The level of significance was set at $p<0.05$.

Results: Wilcoxon matched-pairs signed-ranks test revealed significant differences in VAS and NDI in PEMF+EX and PL+EX groups $(p<0.0001)$. Mann-Whitney $(M W)$ Test showed significant decreased in VAS and NDI scores both treatment $(p<0.0001)$ with more significant decrease in PEMF group than PL+EX group.

Conclusion: PEMF combined with exercise was effective more than exercises alone in decreasing the scores of VAS and NDI in Chronic MNP.

KEY WORDS: Chronic MNP, Exercise, Neck disability index, Pain, Pulsed electromagnetic field.

Address for correspondence: Dr. Mohamed Salaheldien Alayat., PT PhD., Assistant Professor of Physical Therapy, Department of Basic Science, Faculty of Physical Therapy, Cairo University, Egypt.

E-Mail: mohsalahpt@hotmail.com

\section{Access this Article online}

Quick Response code

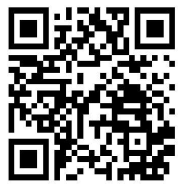

DOI: $10.16965 /$ ijpr.2017.105
International Journal of Physiotherapy and Research

ISSN 2321- 1822

www.ijmhr.org/ijpr.html

Received: 10-01-2017

Accepted: 09-02-2017

Peer Review: 11-01-2017

Published (0): 11-04-2017

Revised: None
Published (P): 11-04-2017 


\section{INTRODUCTION}

Mechanical neck pain (MNP) is a common neck disorders. The patient feel pain between the neck and shoulder regions starting from the nuchal line to the first thoracic spinous process [1] accompanied by local area of tenderness and limitation in the cervical range of motion (ROM) [2]. MNP is common affecting $30 \%$ to $50 \%$ of the middle aged population [3]. Bad neck postures, neck movement, or palpation of the neck region may provoked pain [4]. MNP causing severe discomfort affect patient's daily life and ability to work $[5,6]$. It is characterized by structures and functional features within the cervical spine when it persisted, it is developed into chronic MNP [7-9].

The exact cause of chronic MNP is not completely clear [5]. In addition to psychosocial stress, the existence of mechanical factors like prolonged use of computers, maintaining faulty posture for prolonged time and repetitive movements may contribute to the development of chronic MNP $[10,11]$.

The treatment of chronic MNP includes pharmacological [12] and non-pharmacological interventions. The non-pharmacological treatment may include manual therapy [13], massage [14] and neck exercises [13]. The American Food and Drug Administration (FDA) permit the use of PEMF as a modality for treatment of pain [15]. There is increasing evidences for using magnetic fields for treatment of chronic musculoskeletal pain, muscle soreness and neuropathy [16]. Many studies investigated the effect of either static magnet or pulsed electromagnetic field (PEMF) on chronic pain in rheumatoid arthritis, fibromyalgia [17] and lumbar spondylosis [18] as well as in pain and stiffness associated with delayed onset muscle soreness [19] or in postoperative pain [20]. While the researchers reported significant decreased in pain score $[17,18]$, others reported lack of efficacy in controlling pain, improving performance of soccer-specific fitness performance test performance [21] or recovery of delayed onset muscle soreness [19].

For the available literature, with the lack of evidences supporting the use of PEMF as one of physical therapy interventions used in the treat ment of patient with chronic MNP, therefore the aim of this study was to investigate the effect of PEMF on pain and functional improvement in chronic MNP.

\section{SUBJECTS AND METHODS}

This study design was a randomized controlled trial. In order to examine the effect of PEMF on chronic MNP, patients were randomized into two groups. Group one received PEMF plus exercises (PEMF+EX) and group two received Placebo PEMF plus exercises (PL+ EX). The University's Ethics in Research Committee (local registry number 43409007), Umm Al-Qura University, approved the study. The study has been performed in accordance with the ethical standards as laid down in the 1964 Declaration of Helsinki and its later amendments or comparable ethical standards.

To calculate number of patients, a preliminary power analysis was done by G-power program for windows with $0.05 \alpha$ probability error, 0.80 power (1- $\beta$ error probability), using t east to calculate the difference between two independent means (two groups) with allocation ratio of patients to two groups was 1:1. The effect size chosen was based on a pilot study of changing in pain score (from 7 to $3.2 \pm 1.5$ ) measured by visual analogue scale (VAS) with $r=0.80$ and Cohen's $d=-2.71$. The estimated sample size was 52 patients for both groups. A number was increased to 30 patients in each groups for possible dropout.

Patients were recruited from AL-Noor hospital, Mecca, Saudi Arabia. Treatment of All patients was done at Physical Therapy department, Faculty of Applied Medical Science, Mecca Saudi Arabia. A rheumatologist examined patients before a decision was made to include them in the study. Patients with their age from 20 to 30 years were included in the study if they had chronic MNP for at least 3 months' duration. Pain with local area of tenderness was allocated in the neck, shoulders and/or inter-scapular area at rest or at neck movements. The patients did not take any anti-inflammatory, analgesic and muscle relaxant drugs through the course of the study.

The patients were excluded if they had a referred pain to upper arm or with a positive motor, 
reflex, or sensory abnormalities indicating spinal root compression. Patients with a systemic rheumatological disease as rheumatoid arthritis and/or congenital malformation, trauma, cerebrovascular abnormalities, previous cervical spine surgery or stenosis were also excluded in the study.

After baseline evaluation, patients were selected to participate in the study by give them numbers from 1 to 60 . Patients were randomized into two groups by random number generator using graph Pad on web. The patients were volunteered to participate in the study. A full explanation was given to all patients about nature of the study and the course of treatment, which consists of 12 treatments sessions, given twice a week for 6 weeks. All Patients signed a written informed consent included their agreement for participation in the study. An exercise handout was given to every patient that included the exercises program.

Assessment of pain: A visual analogue scale (VAS) is an ordinal scale, using a $10-\mathrm{cm}$ line divided into 10 equal sections, with 10 representing "unbearable pain" and 0 representing "no pain". For all patients, VAS was used for the assessment of neck pain [22]. Each patient was asked to indicate on the scale the level of pain in the neck at the baseline and post treatment after the end of sessions.

Assessment of neck functions: A neck disability index (NDI) was used for the assessment for neck function status [23]. The NDI is considered as valid and reliable measurement tool in patients with neck pain [24]. The NDI composed of items which measure self-perceived disability from neck pain. Each item was recorded out of 5 for a total score of 50 [25]. Each question has six answers from 0 to 5 , and the patient make a mark in each section, which most closely described their problem. An Arabic version of the NDI was used for all patients. Each patient was asked to fill the index at the baseline and post treatment at the end of treatment sessions.

\section{INTERVENTION PROTOCOLS}

Pulsed electromagnetic field stimulation: Patients in PEMF group received magnetotherapy produced by the device (ASA, Arcugnano Italy). PEMF electrodes were positioned to posterior neck and upper thoracic region while the patient in supine lying position. Magnetotherapy was applied with low frequency $(20 \mathrm{~Hz})$, intensity of 0.8 milliTesla (mT) and time of application 20 minutes applied two sessions/ week for 6 weeks. Magnetotherapy was calibrated for constant output at the physical therapy Department, Faculty of Applied Medical Science, Umm Al-Qura University.

Patients in $\mathrm{PL}+\mathrm{EX}$ group received placebo treatment at the same interval of the active PEMF. In placebo treatment, PEMF electrodes were positioned in the same technique but there was no field during the time of treatment.

Exercises: Patients in both treatment groups received a program of exercises. Exercise program included active range of motion (ROM), muscle stretching and strengthening exercises. Active neck ROM exercise was applied in pain free range with 10 repetitions in all directions. Then patients started stretching exercises program for the upper fibers of trapezius and sternomastoid muscles. After 5 minutes rest, patients performed isometric strengthening exercises for the for the neck extensors, side bending and rotator muscles 10 times/set for three sets with 5 minutes rest in between. The same therapist performed the exercises twice a week for 6 weeks with advices to all patients to repeat the exercises at home.

Outcomes measured: Demographics like age, weight, height, and disease duration were recorded. Baseline assessment of the measured variables were performed at the beginning of the study, and performed at the last session post treatment. The measured outcomes were pain level and disability scores. Pain level was measured by VAS and neck function was measured by NDI.

Data analysis: Analysis was performed using Statistical Package for the Social Sciences (SPSS) for Windows, version 16 (SPSS Inc., Chicago, IL, USA) and Graph Pad InStat (Graph Pad Software, Inc., San Diego, CA, USA).

\section{RESULT}

A total of 60 male patients participated in this study. Both PEMF+ EX and PL + EX groups were consisted of 30 patients. Their mean age, weight, height, body mass index (BMI) and 
duration of illness were 23.03 (2.239) years, $63.43(5.195) \mathrm{Kg}, 1.662(5.1092) \mathrm{cm}, 22.98$ $(1.879) \mathrm{Kg} / \mathrm{m}^{2}, 4.483(1.228)$ months respectively. Testing for homogeneity of variance was performed by two-sample Kolmogorov-Smirnov normality test and it revealed that the baseline mean values passing a normality test with a non-significant difference in baseline mean values ( $p>0.01)$. Also, there were no significant differences between both treatment groups in their mean age, weight, height, BMI and duration of illness as shown in Table 1.

Table 1: Demographic characteristics of patients in both treatment groups.

\begin{tabular}{|c|c|c|c|}
\hline & $\begin{array}{c}\text { PEMF } \\
\text { (mean } \pm \text { SD) }\end{array}$ & $\begin{array}{c}\text { PL+EX } \\
\text { (mean } \pm \text { SD) }\end{array}$ & P value \\
\hline Age & $22.6 \pm 2.14$ & $23.47 \pm 2.29$ & $0.1352^{\mathrm{c}}$ \\
\hline Weight & $64.03 \pm 5.14$ & $62.83 \pm 5.27$ & $0.3756^{\mathrm{c}}$ \\
\hline Height & $166.73 \pm 4.92$ & $165.7 \pm 5.33$ & $0.4382^{\mathrm{c}}$ \\
\hline BMI $\left(\mathrm{Kg} / \mathrm{m}^{2}\right.$ ) & $23.067 \pm 2.014$ & $22.896 \pm 1.765$ & $0.7268^{\mathrm{C}}$ \\
\hline Duration of illness & $4.367 \pm 1.189$ & $4.6 \pm 1.276$ & $0.4665^{\mathrm{C}}$ \\
\hline
\end{tabular}

BMI: body mass index, SD: Standard deviation c: Nonsignificant changes

Table 2: Changes of VAS and NDI in both treatment groups.

\begin{tabular}{|c|c|c|c|c|c|c|}
\hline & \multicolumn{3}{|c|}{ VAS } & \multicolumn{3}{|c|}{ NDI } \\
\hline & PEMF & PL+EX & Pvalue & PEMF & PL+EX & $\mathrm{p}$ value \\
\hline Pre & $7.967 \pm 0.81$ & $8.067 \pm 0.78$ & $0.6872^{c}$ & $44.77 \pm 5.41$ & $45.63 \pm 4.43$ & $0.6238^{c}$ \\
\hline Post & $2.17 \pm 0.91$ & $3.033 \pm 0.67$ & $0.0004^{a}$ & $7.63 \pm 1.77$ & $11.53 \pm 1.55$ & $<0.0001^{\mathrm{a}}$ \\
\hline$p$ value & $<0.0001^{b}$ & $<0.0001^{b}$ & & $<0.0001^{b}$ & $<0.0001^{b}$ & \\
\hline $\begin{array}{c}\text { Cohen effect } \\
\text { size d }\end{array}$ & $1.08, \mathrm{C}$ & $8-1.622)$ & & $2.344, \mathrm{Cl}$ & $-3.002)$ & \\
\hline
\end{tabular}

VAS: Visual analogue scale; NDI: Neck Disability Index $\mathrm{Cl}$ : Confidence interval.

a: Significant differences between treatment groups; Mann Whitney test, $\mathrm{p}>0.05$

b: Significant differences in each treatment group; Wilcoxon matched-pairs signed-ranks test, $p>0.05$ c: Non-significant differences.

Mann-Whitney (MW) Test was used to compare between baseline values of VAS and NDI scores in both treatment groups. It showed non-significant differences as shown in table 2. Comparing between both treatment groups in post treatment VAS and NDI scores showed significant differences as shown in table 2. Wilcoxon matched-pairs signed-ranks test was used to compare between the baseline and post treatment values of VAS and NDI scores. It revealed significant differences in both VAS and NDI in both $\mathrm{PEMF}+\mathrm{EX}$ and $\mathrm{PL}+\mathrm{EX}$ groups (Table 2). Values of VAS and NDI at post treatment decreased PEMF group more than PL+EX group.
Cohen effect size was calculated to compare the changes in $P E M F+E X$ to that of $P L+E X$ and reveled a moderate effect size of VAS and NDI as shown in Table 2.

\section{DISCUSSION}

This study was conducted to investigate the effect of PEMF in combination with exercises on pain and neck functions in patients with chronic MNP. The finding in the current study was that PEMF combined with exercise was effective more than exercises alone in decreasing the scores of VAS and NDI after 6 weeks of treatment.

Magnetic therapy has a long history in the treatment of various medical conditions to improve the recovery of various health problems [26]. Doctors from Greece, China, Japan, and Europe successfully used the magnet in their practice to treat patients [15]. Nowadays,magnetothe rapy is considered as a safe, easy and noninvasive physical therapy modality used to treat pain, inflammation and other types of pathologies and diseases [15].

Magnetic therapy can be applied in different modes. It may be continuous magnetic fields, low-frequency sinusoidal waves, PEMF and transcranial magnetic stimulation [27]. Researchers used many forms of small magnet or large magnetic equipment with a major claim given by researchers to the effect of these magnetic products to be considered as pain relieving modality $[20,21,19]$ as in low back pain [28], heel pain [29] and muscle pain [30].

On the other hand, researchers used the transcranial magnetic stimulation for the treatment of depression [31] or use the small magnet to stimulate the trigger point [32]. The result found significant effect of magnetic stimulation for relief of pain. Studies showed that pulsed, low frequency sinusoidal magnetic fields have been shown to alter pain perception and affect thermal sensory and pain thresholds in patients with rheumatoid arthritis and fibromyalgia. $[33,17]$.

Despite the increasing popularity of magnetic therapy, there is a relatively little number of the available researches which discuss the efficacy of magnetotherapy and its use [34]. Although PEMF is considered as a pain relief modality, 
the underlying mechanisms remain unclear [35]. Researchers attempt to explain the mechanism of action as PEMF causes flow of electrical charges which in turn causing a flow of ionic current necessary for restoration of basic cellular activities and the stimulation of growth factor [36]. Another explanation that describe the mechanisms of action of magnetic therapy is through the magnetic induction, magnetomechanical effects and electronic interactions with cellular functions and is responsible for the increasing blood flow, reducing pain, antiinflammatory, anti-edematous and spasmolytic activity and healing acceleration [37].

Magnetotherapy increased the local blood flow which may speed tissue recovery and cause pain relief [27]. It may also alter the body fluids $\mathrm{pH}$, increase the enzyme activity and pain thresholds in free nerve endings [38]. Moreover, researches suggested that PEMF decrease pain and restricted spinal mobility $[39,18]$, relieve the myofascial pain [40] and effectively reduce cervical spondylotic pain [41].

The results of the present study showed that there was a significant difference between both groups regarding pain level and neck functions. It could be postulated that PEMF had analgesic effect as shown in the PEMF group. Because the MNP was chronic lasting for long duration before therapy, the improvement could not be spontaneous recovery. In addition, the study had control group which get placebo FEMF and exercises and they show no such improvement as in the PEMF group who receive active PEMF. That may exclude the possible effect of placebo treatment.

\section{CONCLUSION}

It was concluding that the PEMF stimulation combined with exercises was more effective than exercises alone in the treatment of patients with chronic MNP.

Recommendation: Magnetotherapy is a physical therapy modality that could be used in combination with exercises in the treatment of patients with chronic MNP for better outcomes.

Limitations: The patients were recruited from the male section of the rehabilitation department in the hospital, and therefore all patients were male. All patients were instructed to perform exercises at home, and a report of exercise compliance was obtained from family members. Despite neither the family members nor the participants themselves reporting any deficiency in the exercise prescription at home, we considered this to be a limiting factor in the present study.

Funding: This research received no specific grant from any funding agency in the public, commercial, or non-profit sectors.

\section{ACKNOWLEDGEMENTS}

The authors express their appreciation to all subjects who participated in this study with all content and cooperation, and give special thanks to their colleagues at the Department of Physical Therapy, Faculty of Applied Medical Science, Umm AL-Qura University, Saudi Arabia.

\section{Conflicts of interest: None}

\section{REFERENCES}

[1]. Bogduk N, McGuirk B. Management of acute and chronic neck pain : an evidence-based approach. 2006; Elsevier, Edinburgh; New York.

[2]. Wood TG, Colloca CJ, Matthews R (2001) A pilot randomized clinical trial on the relative effect of instrumental (MFMA) versus manual (HVLA) manipulation in the treatment of cervical spine dysfunction. J Manipulative Physiol Ther 2001;24 (4):260-271. doi:10.1067/mmt.2001.114365.

[3]. Falla D, Farina D. Muscle fiber conduction velocity of the upper trapezius muscle during dynamic contraction of the upper limb in patients with chronic neck pain. Pain 2005;116 (1-2):138-145. doi:10.1016/j.pain.2005.03.038.

[4]. Gonzalez-Iglesias J, Fernandez-de-las-Penas C, Cleland JA, Gutierrez-Vega Mdel R. Thoracic spine manipulation for the management of patients with neck pain: a randomized clinical trial. J Orthop Sports Phys Ther 2009;39(1):20-27. doi:10.2519/ jospt.2009.2914.

[5]. Viljanen M, Malmivaara A, Uitti J, Rinne M, Palmroos $P$, Laippala P. Effectiveness of dynamic muscle training, relaxation training, or ordinary activity for chronic neck pain: randomised controlled trial. BMJ (Clinical research ed) 2003;327(7413):475. doi:10.1136/bmj.327.7413.475.

[6]. Jull GA, O'Leary SP, Falla DL. Clinical assessment of the deep cervical flexor muscles: the craniocervical flexion test. J Manipulative Physiol Ther 2008;31(7):525-533.doi:10.1016/j.jmpt. 2008.08.003. 
[7]. Falla D, Bilenkij G, Jull G. Patients with chronic neck pain demonstrate altered patterns of muscle activation during performance of a functional upper limb task. Spine (Phila Pa 1976) 2004;29(13):14361440.

[8]. Falla DL, Jull GA, Hodges PW. Patients with neck pain demonstrate reduced electromyographic activity of the deep cervical flexor muscles during performance of the craniocervical flexion test. Spine (Phila Pa 1976) 2004;29 (19):2108-2114.

[9]. Celenay ST, Akbayrak T, Kaya DO. A Comparison of the Effects of Stabilization Exercises Plus Manual Therapy to Those of Stabilization Exercises Alone in Patients With Nonspecific Mechanical Neck Pain: A Randomized Clinical Trial. J Orthop Sports Phys Ther 2016;46 (2):44-55. doi:10.2519/jospt.2016.5979.

[10]. 10. Bongers PM, ljmker S, van den Heuvel S, Blatter BM. Epidemiology of work related neck and upper limb problems: psychosocial and personal risk factors (part I) and effective interventions from a bio behavioural perspective (part II). Journal of occupational rehabilitation 2006;16 (3):279-302. doi:10.1007/s10926-006-9044-1.

[11]. Cote P, van der Velde G, Cassidy JD, Carroll LJ, HoggJohnson S, Holm LW, Carragee EJ, Haldeman S, Nordin M, Hurwitz EL, Guzman J, Peloso PM. The burden and determinants of neck pain in workers: results of the Bone and Joint Decade 2000-2010 Task Force on Neck Pain and Its Associated Disorders. Spine (Phila Pa 1976) 2008;33(4 Suppl):S60-74. doi:10.1097/BRS.0b013e3181643ee4

[12]. Seo BK, Lee JH, Kim PK, Baek YH, Jo DJ, Lee S. Bee venom acupuncture, NSAIDs or combined treatment for chronic neck pain: study protocol for a randomized, assessor-blind trial. In: Trials 2014;15. England, p 132. doi:10.1186/1745-6215-15-132.

[13]. Akhter S, Khan M, Ali SS, Soomro RR. Role of manual therapy with exercise regime versus exercise regime alone in the management of non-specific chronic neck pain. Pak J Pharm 2014;Sci 27 (6 Suppl):21252128.

[14]. Bakar Y, Sertel M, Ozturk A, Yumin ET, Tatarli N, Ankarali $\mathrm{H}$. Short term effects of classic massage compared to connective tissue massage on pressure pain threshold and muscle relaxation response in women with chronic neck pain: a preliminary study. J Manipulative Physiol Ther 2014;37(6):415421. doi:10.1016/j.jmpt.2014.05.004.

[15]. Markov MS. Pulsed electromagnetic field therapy history, state of the art and future. The Environmentalist 2007;27(4):465-475. doi:10.1007/s10669007-9128-2.

[16]. Weintraub MI, Cole SP. Pulsed magnetic field therapy in refractory neuropathic pain secondary to peripheral neuropathy: electrodiagnostic parameters-pilot study. Neurorehabilitation and neural repair 2004;18(1):42-46.doi:10.1177/088843900 3261024.

[17]. Shupak NM, McKay JC, Nielson WR, Rollman GB, Prato FS, Thomas AW. Exposure to a specific pulsed low-frequency magnetic field: a double-blind placebo-controlled study of effects on pain ratings in rheumatoid arthritis and fibromyalgia patients. Pain research \& management 2006;11(2):85-90.

[18]. Zdrodowska B, Leszczynska-Filus M, Leszczynski R, Blaszczyk J. Comparison of the effect of laser and magnetic therapy for pain level and the range of motion of the spine of people with osteoarthritis lower back. Polski merkuriusz lekarski : organ Polskiego Towarzystwa Lekarskiego 2015;38 (223):26-31.

[19]. Mikesky AE, Hayden MW Effect of static magnetic therapy on recovery from delayed onset muscle soreness. Physical Therapy in Sport 2005;6(4):188-194. doi:10.1016/j.ptsp.2005.08.004.

[20]. Cepeda MS, Carr DB, Sarquis T, Miranda N, Garcia RJ, Zarate C (2007) Static magnetic therapy does not decrease pain or opioid requirements: a randomized double-blind trial. Anesthesia and analgesia 2007;104(2):290-294. oi:10.1213/01.ane .0000 230 613.25754 .08

[21]. Schall DM, Ishee JH, Titlow LW (2003) Effect of magnetic therapy on selected physical performances. Journal of strength and conditioning research / National Strength \& Conditioning Association 2003;17(2):299-302.

[22]. Carlsson AM. Assessment of chronic pain. I. Aspects of the reliability and validity of the visual analogue scale. Pain 1983;16(1):87-101.

[23]. Wlodyka-Demaille S, Poiraudeau S, Catanzariti JF, Rannou F, Fermanian J, Revel M. The ability to change of three questionnaires for neck pain. Joint, bone, spine: revue du rhumatisme 2004;71(4):317326. doi:10.1016/j.jbspin.2003.04.004.

[24]. Shaheen AA, Omar MT, Vernon H (2013) Cross-cultural adaptation, reliability, and validity of the Arabic version of neck disability index in patients with neck pain. Spine (Phila Pa 1976) 2013;38(10):E609615. doi:10.1097/BRS.0b013e31828b2d09.

[25]. Yao M, Sun YL, Cao ZY, Dun RL, Yang L, Zhang BM, Jiang HR, Wang YJ, Cui XJ. A Systematic Review of Cross-cultural Adaptation of the Neck Disability Index. Spine (Phila Pa 1976) 2015. doi:10.1097/ brs.0000000000000788.

[26]. Omar AS, Awadalla MA, El-Latif MA. Evaluation of pulsed electromagnetic field therapy in the management of patients with discogenic lumbar radiculopathy. International journal of rheumatic diseases 2012;15 (5):e101-108. doi:10.1111/j.1756185X.2012.01745.x.

[27]. Turan Y, Bayraktar K, Kahvecioglu F, Tastaban E, Aydin E, Kurt Omurlu I, Berkit IK. Is magnetotherapy applied to bilateral hips effective in ankylosing spondylitis patients? A randomized, double-blind, controlled study. Rheumatol Int 2014;34 (3):357365. doi:10.1007/s00296-013-2941-7.

[28]. Collacott EA, Zimmerman JT, White DW, Rindone JP (2000) Bipolar permanent magnets for the treatment of chronic low back pain: a pilot study. In: JAMA, 2000;283(10):1322-1325.

[29]. Winemiller MH, Billow RG, Laskowski ER, Harmsen WS (2003) Effect of magnetic vs sham-magnetic 
insoles on plantar heel pain: a randomized controlled trial. In: JAMA, 2003;290(11):1474-1478. doi:10.1001/jama.290.11.1474

[30]. Borsa PA, Larkin KA, True JM. Does phototherapy enhance skeletal muscle contractile function and postexercise recovery? A systematic review. Journal of athletic training 2013;48 (1):57-67. doi:10.4085/1062-6050-48.1.12.

[31]. George MS, Wassermann EM, Kimbrell TA, Little JT, Williams WE, Danielson AL, Greenberg BD, Hallett $M$, Post RM. Mood improvement following daily left prefrontal repetitive transcranial magnetic stimulation in patients with depression: a placebo-controlled crossover trial. The American journal of psychiatry 1997;154 (12):1752-1756. doi:10.1176/ ajp.154.12.1752

[32]. Vallbona C, Hazlewood CF, Jurida G. Response of pain to static magnetic fields in postpolio patients: a double-blind pilot study. Arch Phys Med Rehabil 1997;78(11):1200-1203.

[33]. Shupak NM, Prato FS, Thomas AW. Human exposure to a specific pulsed magnetic field: effects on thermal sensory and pain thresholds. Neuroscience letters 2004;363 (2):157-162. doi:10.1016/j.neulet. 2004.03.069.

[34]. Kanat E, Alp A, Yurtkuran M (2013) Magneto-therapy in hand osteoarthritis: a pilot trial. Complement Ther Med 2013;21(6):603-608. doi:10.1016/ j.ctim.2013.08.004.

[35]. Trock DH. Electromagnetic fields and magnets. Investigational treatment for musculoskeletal disorders. Rheum Dis Clin North Am 2000;26(1):51-62.
[36]. Bachl N, Ruoff G, Wessner B, Tschan H. Electromagnetic interventions in musculoskeletal disorders. In: Clin Sports Med, 2008;27(1):87-105. doi:10.1016/j.csm.2007.10.006

[37]. Valentinuzzi ME. Magnetotherapy, alternative medicines, Hippocratic oath. In: Biomed Eng Online, 2008;7:1. doi:10.1186/1475-925x-7-1

[38]. Weintraub MI, Wolfe GI, Barohn RA, Cole SP, Parry GJ, Hayat G, Cohen JA, Page JC, Bromberg MB, Schwartz SL. Static magnetic field therapy for symptomatic diabetic neuropathy: a randomized, doubleblind, placebo-controlled trial. In: Arch Phys Med Rehabil, 2003;84(5):736-746.

[39].Holcomb RR, Worthington WB, McCullough BA, McLean MJ. Static magnetic field therapy for pain in the abdomen and genitals. In: Pediatr Neurol, 2000;23(3):261-264.

[40]. Panagos A, Jensen M, Cardenas DD. Treatment of myofascial shoulder pain in the spinal cord injured population using static magnetic fields: a case series. J Spinal Cord Med 2004;27(2):138-142.

[41]. Trock DH, Bollet AJ, Markoll R. The effect of pulsed electromagnetic fields in the treatment of osteoarthritis of the knee and cervical spine. Report of randomized, double blind, placebo controlled trials. J Rheumatol 1994;21 (10):1903-1911.

How to cite this article:

Mohamed Salaheldien Alayat, Mohamed Mohamed Ibrahim Ali, Amir Abdel

Raouf El Fiky, Mansour Abdullah Alshehri. EFFICACY OF PULSED ELECTROMAGNETIC FIELD ON PAIN AND FUNCTION IN CHRONIC MECHANICAL NECK PAIN: A RANDOMIZED CONTROLLED TRIAL. Int J Physiother Res 2017;5(2):1930-1936. DOI: 10.16965/ijpr.2017.105 